\title{
POLA KEPEMIMPINAN DAN SISTEM MANAJEMEN PENDIDIKAN DI BEBERAPA NEGARA PERSEMAKMURAN: Suatu Kajian Analisa perbandingan
}

\author{
Afdhal \\ Jurusan Geografi, Fakultas Ilmu Sosial Universitas Negeri Padang \\ Korespondensi: Perumahan Bunga Mas II Blok AH No. 12, Bungo Pasang, Kec Koto Tangah, Padang \\ Sumatera Barat 25176, Telp (0751) 444741
}

\begin{abstract}
Leadership pattern and management system will determine education quality of a country. The commonwealth countries have applied such pattern and system which are similar to their educational management. Australia, Canada, and England, for example, have reformed their educational system. As a result, they can produce good quality of education. This article analyzes leadership pattern and management system in the three mentioned commonwealth countries. By conducting comparison analysis, this situation is expected to be a guidance and example for educational management in Indonesia which in turn will improve the education quality.
\end{abstract}

Kata kunci: pola kepemimpinan pendidikan, sistem manajemen pendidikan

\section{PENDAHULUAN}

$\mathrm{P}$ erbaikan kualitas pendidikan selalu menjadi pusat perhatian, baik oleh pemerintah (daerah maupun pusat), ahli pendidikan (secara individu maupun berkelompok), dan unsur lain dalam masyarakat yang peduli pada dunia pendidikan. Semua komponen ini pada dasarnya menginginkan hal yang sama, yaitu hasil pendidikan yang berkualitas, sesuai dengan tuntutan masyarakat, serta pengelolaan dan kepemimpinan penddidikan yang efektif dan efisien. Disamping itu mereka juga berharap agar dunia pendidikan juga tanggap terhadap perubahan-perubahan yang terjadi dalam masyarakat, seperti perubahan pengetahuan, teknologi, sosial, ekonomi, politik dan budaya, dan mampu menyerap semua perubahan dimaksud. Oleh karena itu penyelenggaraan pendidikan harus berkemampuan untuk memenuhi setiap harapan masyarakat dimaksud.

Levin (dalam Fullan,1991) mengatakan ada tiga penyebab perlunya perubahan kebijakan dalam bidang pendidikan, yaitu: satu, bencana alam, seperti banjir, gempa bumi, gunung meletus; dua, tekanan dari luar seperti masuknya ilmu, teknologi serta nilainilai baru dari luar; dan tiga, adanya kontradiksi internal dan eksternal seperti perubahan teknologi yang menyebabkan perubahan kebutuhan, pola hubungan sosial, dan harapan dalam masyarakat. Vann (1995) mengidentifikasi beberapa faktor penyebab perlunya reformasi dalam dunia pendidikan, diantaranya adalah resesi ekonomi, perubahan manufaktur dan komunikasi, keingin tahuan para pembayar pajak terhadap penggunaan uang pajak mereka dan rendahnya angka keberhasilan siswa dalam belajar Selajutnya, Duignan dan Mac 
Phearson (1993) mengatakan bahwa keinginan yang tinggi dari stakeholders untuk berpartisipasi dalam pengambilan keputusan di sekolah dan harapan mereka agar mutu sekolah diperbaiki. Karena alasan-alasan ini, para pengambil kebijakan dalam bidang pendidikan harus memberikan perhatian yang serius terhadap cara pengelolaan pendidikan yang baik sehingga dapat mengingktkan kualitas pendidikan.

Kualitas pendidikan pada dasarnya ditentukan oleh proses pembelajaran yang dilakukan di sekolah. Oleh karena itu, pembaharuan dalam pendidikan hendaklah ditujukan pada perbaikan dan peningkatan proses pembelajaran di sekolah. Untuk dapat mencapai tujuan ini, maka pola kepemimpinan dan sistem pengelolaan pendidikan harus dirobah agar lebih responsive terhadap tuntutan perkembangan zaman dan masyarakat. Vann (1995) menyatakan bahwa pola pengelolaan pendidikan yang efektif untuk meningkatkan kualitas pendidikan adalah dengan memberikan kewenangan (power) kepada stakeholders (pemerintah, administrator pendidikan, orang tua siswa, guru, kepala sekolah dan masyarakat) dalam merumuskan atau membuat kebijakan-kebijakan kependidikkan. Dengan cara memberikan power kepada stakeholders untuk membuat kebijaksanaan pendidikan, manajemen sekolah dan kebutuhan masyarakat dapat secara continius ditingkatkan dan terjadi saling keterbukaan serta sa-ling memahami satu sama lain. Akibatnya manajemen pendidikan akan berpindah dari sistem sentralisai menjadi sistem desntralisasi. Melalui sistem desentralisasi ini kesempatan stakeholder untuk berpartisipasi dalam pengambilan keputusan disekolah terbuka lebar sehingga dapat mengurangi keterasingan sekolah dari masyarakat, meningkatkan kepuasan kerja guru-guru, membangkitkan kesadaran seluruh lapisan masya- rakat akan pentingnya partisipasi mereka dalam penyelenggaraan pendidikan

Tulisan ini akan membahas tentang reformasi pola kepemimpinan dan sistem manajemen pendidikan yang terjadi di beberapa Negara persemakmuran seperti, Australia, Canada dan Inggris. Pembahasannya akan difokuskan pada reformasi sistem pengelolaan sekolahsekolah negeri. Pembahasan ini diharapkan dapat memberikan gambaran kepada kita bagaimana pengelolaan pendidikan dinegara-negara tersebut, yang mungkin nantinya akan dapat menjadi acuan dalam rangka memperbaiki dan mereformasi manajemen pendidikan di Indonesia.

\section{POLA KEPEMIMPINAN DAN SIS- TEM MANAJEMEN PENDIDIKAN DI AUSTRALIA}

Reformasi dunia pendidikan di seluruh Negara bagian Australia dimulai sejak tahun 1981 ketika hasil analisa tentang sekolah-sekolah dan college (white papper) dipublikasikan. White papper ini memusatkan perhatian pada pemindahan secara progresif kewenangan pendidikan disekolah, khususnya kewenangan tentang pengadaan guru, pemeliharaan dan perbaikan sarana sekolah dan pembiayaan (Caldwell, 1991). Reformasi sistem manajemen yang direkomendasikan oleh white papper bertujuan untuk meningkatkan efisiensi dan efektifitas dalam pengelolaan sekolah di Australia. Beberapa reformasi yang menarik adalah dengan dibentuknya departement of education and art (DEA). dan pemindahan tanggung jawab pengelolaan dan pembiayaan ketingkat sekolah dan college, dan tahap ujicobanya dilaksanakan tahun 1983 s/d 1989 ternyata berhasil. Kenyataan ini menunjukkan bahwa white papper telah merekomendasikan kewenangan yang penuh kepada sekolah dan college dalam mengelola sekolah. 
Pada bulan juni 1990 pemerintah Negara bagian Tasmania meminta badan konsultan pendidikan di Melbourne (Negara bagian Victoria) yang bernama Cresap, untuk mempelajari (review) sistem manajemen pendidikan di Tasmania. Hasil dari review ini merekomendasikan:

1. Pengelompokan sekolah di Tasmania harus diubah dari 3 (tiga) regional (scholl regional) menjadi 8 (delapan) kelompok district (school district), yang masing-masing scholl district mempunyai kewenangan sendiri dalam mengambil keputusan.

2. Dana sekolah didasarkan pada jumlah siswa yang terdaftar pada suatu sekolah.

3. Masing-masing sekolah mempunyai kewenangan yang tinggi dalam mengelola sekolahnya (Caldwell, 1991).

Berdasarkan rekomendasi cresap ini, manajemen sekolah berpindah dari sistim sentralisasi menjadi sitim desentralisasi. Namun 8 scholl district yang direkomendasikan hanya 7 saja yang ditetapkan oleh pemerintah Negara bagian Tasmania, dimana masing-masing scholl district dipimpin oleh seorang superintendent yang dibantu oleh beberapa orang staf. Reformasi sistem dan struktur manajemen pendidikan di Tasmania ini berkembang dan menjadi model keseluruh daratan Australia. Adapun Struktur manajemen pendidikan di Australia ini dapat dilihat pada diagram di bawah ini.

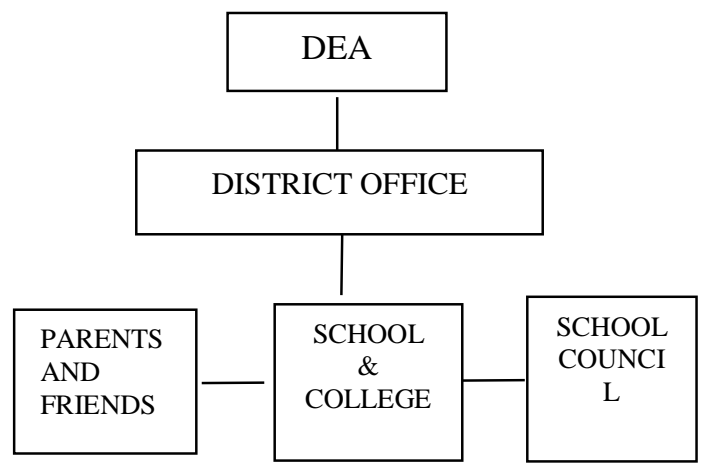

Diagram 1: struktur manajemen pendidikan di Australia
Sekolah sekolah diaustralia mempunyai kurikulum nasional, tetapi $D E A$, scholl district, sekolah dan college mempunyai kebebasan untuk mengembangkan kurikulum dan metode mengajarnya sendiri, yang pengembangan bias berdasarkan kurikulum nasional atau tidak. Dengan kata lain penggunaan kurikulum nasional sebagai guidelines sifatnya adalah pilihan, bukan suatu keharusan. Pemerintah federal membuat kurikulum guidelines, tetapi sekolah mempunyai otonomi untuk mengembangkan kurikulum sendiri, yaitu memutuskan sendiri apa yang akan diajarkan, berapa lama akan diajarkan, dan bagaimana cara mengajarkannya. Dalam kaitnnya bagaimana sekolah dioperasikan (dikelola), DEA membuat aturan dan kebijaksanaan dasar untuk sekolah. Dalam pengimplementasiannya disekolah, sebelum kebijaksaan DEA ini dimplementasikan, kebijakan tersebut dikembangkan dan dirumuskan secara terinci disekolah dan disesuaikan dengan kondisi sekolah oleh kepala sekolah, guru, school council (parents and friends association/P\&F). Kenyataan ini menunjukkan bahwa sistem pendidikan di Australia juga menerapkan sistem manajemen berbasis sekolah.

Dalam hubungannya dengan akuntabilitas setiap sekolah mempunyai school council $(P \& F)$. Kepala sekolah harus mengadakan pertemuan secara berkala dengan school council untuk melaporkan semua kegiatan yang telah dilakukan sekolah. Dengan kata lain sekolah bertanggung jawab terhadap school council. Suatu hal yang sangat menarik adalah kebebasan setiap orang untuk datang dan mengadu tentang ketidakpuasannya dengan pelayanan pendidikkan ke kantor Ministry of Education (DEA). Setiap pengaduan atau keluhan yang diajukan oleh orangtua siswa atau masyarakat, senantiasa mendapat tanggapan yang serius dari Ministry of Education. Ini bararti bahwa secara tidak 
langsung sekolah bertanggungjawab kepada orang tua siswa dan masyarakat.

\section{POLA KEPEMIMPINAN DAN SIS- TEM MANAJEMEN PENDIDIKAN DI CANADA}

Reformasi sistem manajemen pendidikan di Canada dimulai tahun 1989 (The New Scool Act,1989). Dalam sistem ini, manajemen pendidikan berada dibawah pemerintahan Negara bagian, yang tanggung jawab pelaksanaannya diserahkan pada kementrian pendidikan (Ministry of Education). Tugas atau fungsi ministry of education adalah menyediakan kurikulum dan petunjuk umum (guidelines) untuk pengorganisasian sekolah, menginspeksi dan mensupervisi sekolah-sekolah, menyediakan sarana dan prasarana belajar, mengawasi keuangan sekolah, dan memberikan sertifikasi kepada guru. Dengan sistem ini kebijakan pendidikan dibuat pada tingkat Negara bagian. Pada tingkat pusat, tugas pemerintah pusat hanya melakukan evaluasi secara nasional dan akreditasi kepada sekolah-sekolah setiap enam tahun sekali. Kebijaksanaan yang dibuat oleh tingkat Negara bagian, peng- implementasiannya ada dibawah kewenangan daerah (district) dan sekolah.

Komponen manajemen pendidikan pada tingkat district terdiri dari superintendent, assistant superintendent, beberapa orang directur, yang semuanya bekerjasama dengan school board (dewan pengawas sekolah) dan trustees. Anggota school board dipilih dari masyarakat setempat dan mereka dibayar/digaji oleh pemerintah. Komponen manajemen pendidikan pada tingkat sekolah terdiri dari kepala sekolah, guru, badan penasehat sekolah dari orang tua siswa (Parents Advisory Council).

Secara struktural sistem manajemen pendidikan di Canada sudah lebih terdesentralisasi. Tingkat Negara bagian melalui ministry of education, memang mengeluarkan ketentuan-ketentuan (guidelinees), kurikulum, dan lainnya; tapi kewenangan pelaksanaannya terletak pada local board dan sekolah. Sementara itu peran orang tua siswa (Parents Advisory Council) selalu terlibat dalam menentukan tujuan pendidikan, kebijaksanaan pendidikan dan pelayanan-pelayanan yang diberikan untuk anak mereka. Pembiayaan sekolah (school budgeds) perbaikan gedung, pengadaan sarana merupakan tanggung jawab administrato sekolah.

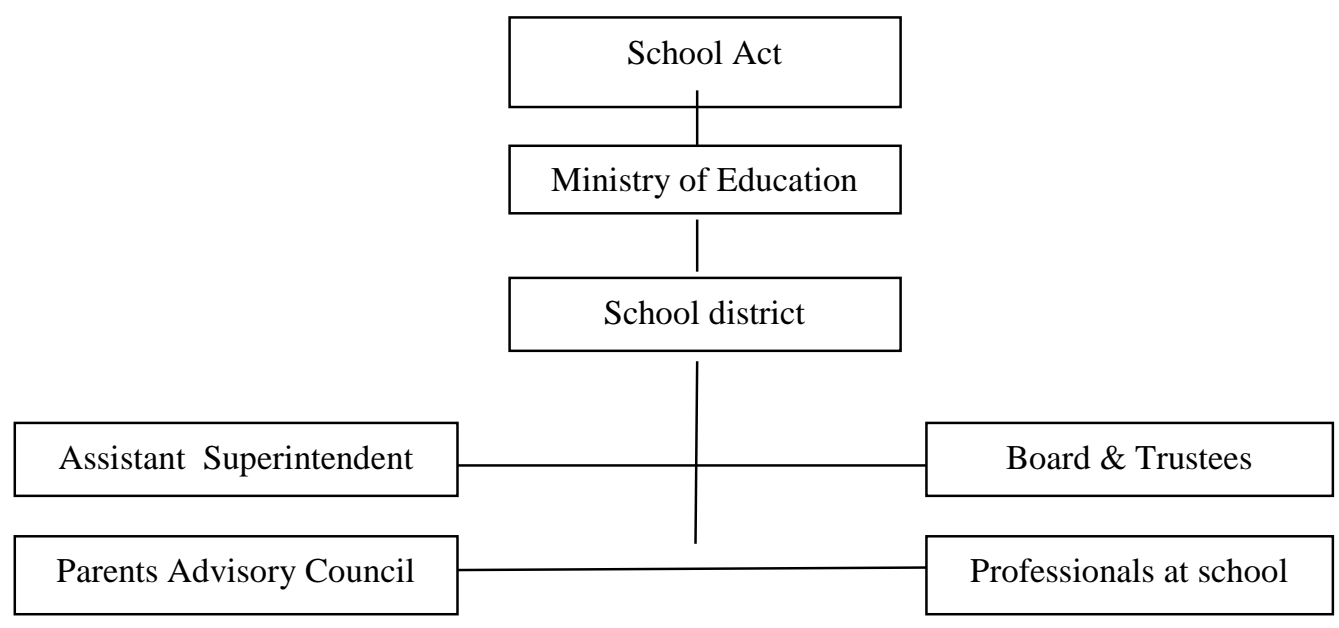

Diagram 2: struktur manajemen pendidikan di Canada

Kenyataan ini menunjukkan bahwa district dan sekolah mempunyai kewe- nangan penuh untuk membuat keputusan berhubungan dengan pengimplementasi- 
an guidelines yang diberikan oleh ministry of education di tingkat Negara bagian. Dengan kata lain, manajemen berbasis sekolah (school based management) juga dilaksanakan di Canada. Struktur manajemen pendidikan di Canada dapat dilihat dalam diagram 2 diatas.

Sebagaimana halnya di Australia, di Canada juga menekankan akuntabilitas sekolah kepada orang tua siswa, siswa, masyarakat dan kepada Ministry of Education melalui School District Board Office. School council atau Parents Advisory Council dan kepala sekolah bersama-sama membuat kebijakan sekolah. Keterlibatan orang tua dan masyarakat dalam merumuskan kebijaksanaan sekolah akan membawa dampak posistif terhadap perbaikan kualitas sekolah, dan memungkinkan adanya relevansi yang tinggi antara apa yang diajarkan disekolah dengan apa yang diinginkan oleh orang tua dan masyarakat.

\section{POLA KEPEMIMPINAN DAN SIS- TEM MANAJEMEN PENDIDIKAN DI INGGRIS}

Reformasi sistem manajemen pendidikan di Inggris lebih lambat bila dibanding dengan australia dan baru dimulai pada tahun 1988, ditandai dengan disahkannya Undand-Undang Perubahan Pendidikan (The Educational Reform Act, 1988). Inti dari reformasi ini adalah mengubah manajemen pendidikkan pada tingkat sekolah (local management of school) yang disingkat LMS. $L M S$ yaitu pemindahan kewenangan dan tanggung jawab pengelolaan pada masing-masing sekolah, dan perubahan gaya manajement sekolah dari sentralisasi ke desentralisasi.

Secara umum, tujuan dari reformasi ini adalah untuk meningkatkan kualitas sekolah yaitu kualitas tamatannya, serta meningkatkan efektifitas dan efisiensi sistem pengelolaan sekolah. Secara khusus, tujuan LMS adalah:

a. To enchance the power of parents and governing bodies at the expense of the local educational authority (LEA)

b. To improve accountability for the use of finance and the resources

c. To the improvement of efficiency with which resources are used in the education services

d. To prvide a more aquitable distribution to schools of the available public fund; and

e. To improve the quality of teaching and learning process (Levacic, 1992 : 16)

Tujuan utama dari LMS adalah meningkatkan efisiensi dan efektifitas pengelolaan sekolah untuk meningkatkan kualitas proses pembelajaran, dan akhirnya akan meningkatkan kualitas tamatan (outcome). LMS adalah pola baru dalam manajemen sekolah dimana sekolah diberi kewenangan untuk membuat keputusan pada tingkat sekolah, menggunakan dana sekolah sesuai dengan kebutuhan dan formula dana yang sudah ditetapkan, dan membentuk suatu sistem pengelolaan dimana masyarakat dilibatkan secara aktifdalam pengambilan keputusan sekolah. Selanjutnya, Levacic (1992: 16) menjelaskan hakekat LMS adalah sebagai suatu pendesentralisasian pembuatan keputusan dan pendelegasian dana pada level sekolah. Dimana dana sekolah di alokasikan berdasarkan formula yang telah ditetapkan. Adapun formula dana alokasi sekolah adalah berdasarkan pada jumlah murid yang terdaftar di sekolah tersebut. Orang tua siswa bebas memilih kesekolah mana mereka akan memasukkan anaknya, dan sekolah dikelola oleh suatu badan (school council) yang anggotanya adalah wakil dari masyarakat.

LMS membagi sistem manajemen sekolah dalam dua tingkatan, yaitu tingkat nasional dan local. Manajemen ting- 
kat nasional fungsinya menyediakan kerangka atau rambu-rambu struktur organisasi dan tujuan pendidikan (termasuk kurikulum nasional), dana pendidikan (LMS Scheme), dan ujian serta penilaian nasional (Nastional Examination and Assesment). Kurikulum nasional yang hanya dalam bentuk kerangka acuan adalah sangat penting agar sekolah dimanapun mempunyai kesempatan yang sama. Secara keseluruhan, manajemen ditingkat nasional akan memberikan arah pada level manajemen yang ada dibawahnya.

Manajemen pada tingkat lokal yaitu $L E A$, Kepala Sekolah, guru, dan stakeholder diberi kewenangan untuk mengidentifikasi apa yang menjadi ke- butuhan sekolah, dan mengambil keputusan yang sesuai dengan keadaan sekolah, termasuk menetapkan visi, misi dan tujuan-tujuan sekolah. Kepala sekolah, LEA, dan pemerintah local (lacal government) mempunyai fungsi dan kewenangan yang jelas terhadap sekolah. Kepala sekolah, sebagai pimpinan sekolah, diawasi an disupervisi oleh LEA dalam penggunan dana. Mutu pendidikkan yang diinginkan oleh para stakeholder dijaga oleh badan pemerintah yang mengontrol mutu lulusan, yaitu Office for Standards in Education (Ofsted). Badan ini akan mengevaluasi sekolah setiap empat tahun sekali. Struktur organisasi pendidikan di Inggris dapat dilihat pada diagram di bawah ini.

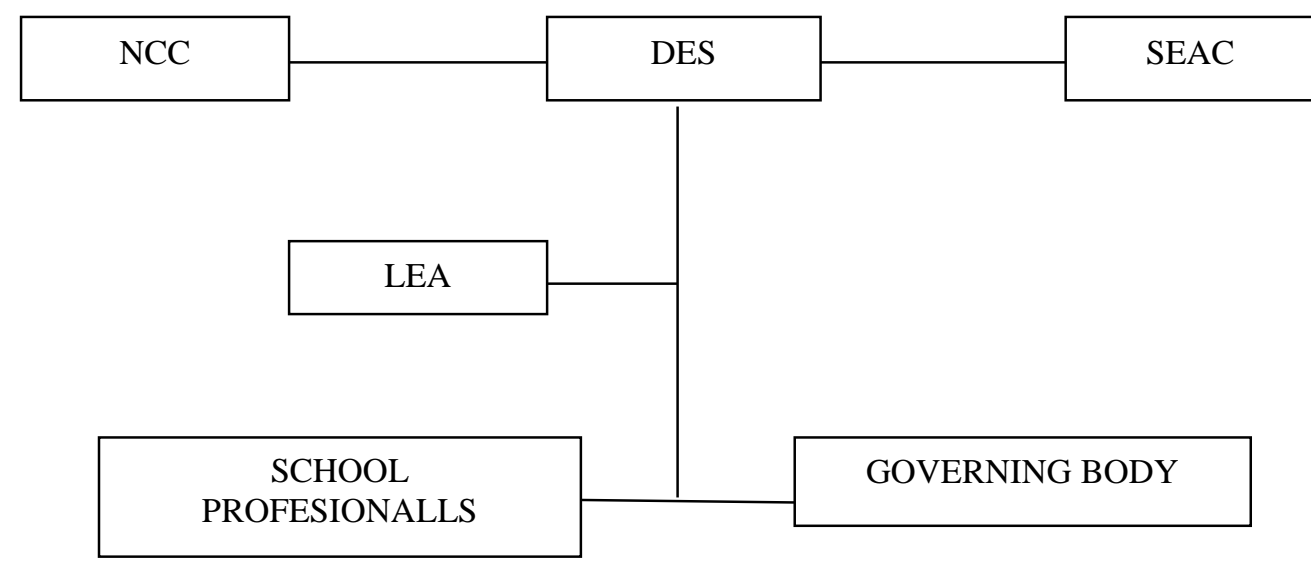

Diagram 3: Struktur Manajemen Pendidikan di inggris

Komponen-komponen utama yang mengoperasikan sekolah adalah kepala sekolah dan badan penasehat sekolah (governing body). Mereka diberi kewenangan untuk mengelola sekolah berdasarkan situasi dan kondisi sekolah masing-masing. Guru, suda barang tentu diberi kesempatan untuk berpartisipasi aktif dalam pembuatn kebijakan sekolah. Kepala sekolah dan badan penasehat sekolah (governing body) bertanggung jawab dan akuntabel terhadap smua kebijakan yang diambil dan proses pendidikkan yang dilaksanakan. Mereka bertanggung jawab terhadap lokal otoritas (LEA) untuk kebijaksanaan yang bersifat lokal, dan bertanggung jawab terhadap orang tua dan murid-murid untuk kebijaksanaan yang dibuat berdasarkan sekolah. Kualitas pendidikan akan dikontrol oleh orang tua dan masyarakat melalui governing body yang secara otomatis akan selalu memastikan adanya relevansiantara lulusan dengan keinginan masyarakat.

Pengaruh reformasi manajemen pendidikan di Inggris, menurut Levacic (1992) adalah: (1) meningkatnya kompetisi dalam penerimaan murid membawa pengaruh besar terhadap sekolah, di mana sekolah selalu berusaha untuk meningkatkan kualitas pendidikan yang disediakannya. (2) murid-murid kana banyak masuk ke sekolah yang berkualitas, 
ini berarti meningkatnya dana sekolah, dan memungkinkan sekolah untuk meningkatkan kualitas pelayanannya. (3) sekolah-sekolah yang tidak efektif akan di tutup.

Dari kenyataan diatas jalaslah bahwa dengan LMS, kualitas sekolah dapat ditingkatkan melalui persaingan yang sehat antara sekolah yang satu dengan sekolah yang lainnya. LMS memberikan otoritas penuh kepada sekolah untuk mngontrol masukannya, prosesnya bersandar pada kurikulum nasional, dan keluarannya dikontrol oleh indikator keberhasilan yang ditetapkan secara nasonal (Davies dan Ellison, 1992).

\section{KESIMPULAN}

Reformasi sistem pendidikan di beberapa Negara persemakmuran (Australia, Canada dan Inggris) telah dilakukan di era delapan puluhan. Ketiga Negara tersebut telah menerapkan sistem manajemen yang lebih terdesentralisasi. Masing-masing pemerintahan telah memberikan kewenangan yang lebih besar kepada kepala sekolah, dan guru untuk mengatur sekolahnya sendiri. Kewenangan juga diberikan kepada orang tua siswa dan masyarakat sekitar sekolah melalui school board atau school committees, agar masyarakat dapat lebih berpartisipasi dalam perumusan kebijakan atau dalam pengambilan keputusan menyangkut pelaksanaan pendidikan di sekolah. Dengan sistem ini, keputusan atau kebijakan menyangkut sekolah dapat dibuat secara bersama-sama antara orang tua siswa, wakil masyarakat, kepala sekolah, guru, dengan tetap memperhatikan garis-garis besar yang sudah dibuat atau dirumuskan oleh Pemerintah Federal atau Negara Bagian (Propinsi). Dengan adanya kerjasama ini, maka efektifitas dan efisiensi pengelolaan sekolah bias ditingkatkan. Proses pembelajaran mencerminkan ke- butuhan masyarakat, usaha perbaikan mutu sekolah akan lebih mudah dilaksanakan dan akhirnya mutu sekolah dapat ditingkatkan.

Jika kita tinjau pula reformasi sistem pendidikan di Indonesia, juga sudah dilaksanakan terutama setelah tahun 2000 seiring dengan UndangUndang Otonomi Daerah. Namun, reformasi baru sebatas pendelegasian urusan administrasi dari pusat ke daerah tingkat I dan tingkat II, sedangkan pendelegasian kewenangan pada tingkat lembaga atau sekolah belum dilaksanakan. Disamping itu, sistem manajemen dan pola kepemimpinan pendidikan di Indonesia masih sangat kompleks. Hal ini dapat dilihat dengan masih berlangsungnya penyelenggaraan pendidikan oleh departemen lain diluar Departemen Pendidikan Nasional. Tidak dapat dipungkiri bahwa sesuatu hal yang sangat janggal dan berbahaya sudah terjadi dimana kepemimpinan pendidikan dan sekolah saat ini sudah dimasuki pula oleh ranah politik.

Jika sistem manjemen pendidikan di Indonesia ingin dibuat lebih efektif dan efisien, dan mutu sekolah lebih ditingkatkan, maka pembaharuan dalam bidang manajemen pendidikan harus segera dilaksanakan oleh pemerintah seperti:

1. Penetapan bahwa tanggung jawab penyelenggaraan pendidikan formal hanya ada pada Departemen Pendidikan Nasional. Departemen lain hanya boleh diberi kewenangan untuk melaksanakan program inservice training untuk pengembangan professional. Dengan demikian, sistem manajemen pendidikan tidak akan menjadi kompleks, dana pendidikan dapat dipusatkan hanya pada satu departemen saja, efektifitas dan efisiensi pengelolaan akan bisa ditingkatkan.

2. Desentralisasi pendidikan juga harus mencakup pendelegasian kewenangan pengelolaan pendidikan ke sekolah 
dan masyarakat. Pemerintah hanya menyediakan dana untuk pendidikan, merumuskan kerangka pendidikan yang akan dilaksanakan, sementara sekolah, orang tua siswa dan masyarakat diberi kewenangan luas untuk menentukan penggunaan dana dan mengisi rambu-rambu yang disediakan sesuai dengan kondisi dan kebutuhan sekolah dan masyarakat. De-

\section{DAFTAR RUJUKAN}

Caldwell, B.J. (1991). Restructuring education in Tasmania: Aturbulent end to decade tranquility. Curtin, ATC: The Australian College Education

Davies, B. dan Ellison, L, (1992). Delegated school finance in English education system: An era of radical change. Journal of educational and administration. Vol 30, No. 1, hal 70-80

Fullan, M. (1991). The new meaning ofeducational change. New York: Teacher College Press.

\section{Daftar Indeks}

budaya, 22

guru, 56, 58, 60, 61

Guru, 61

manajemen, 22, 56, 57, 58, 59, 60, 61, 62

murid, 60, 61 ngan memberikan kewenangan menyeluruh kepada sekolah dan masyarakat dalam merumuskan hal apa saja yang akan dilakukan sekolah, maka sekolah akan lebih responsive terhadap kebutuhan masyarakat setempat. Akhirnya pelaksanaan pendidikan akan menjadi lebih efektif dan efisien dan kualitas pendidikan dapat ditingkatkan.

Levacic, R. (1992). Local management of school: Aims, scope and impact, Educational management and Administration. Vol 20, No. 1, hal 16-29.

Vann,B, (1995). The accountabilityand assessment of school in England and Wales: Current issue of practitioners (unpublish paper). Dibawakan dalam Annual Conference of American Educational Research and Association. San Francisco, 18-22 April 1995

pendidikan, 22, 56, 57, 58, 59, 60, 61, 62

pola, $22,56,60,62$

sekolah, 56, 57, 58, 59, 60, 61, 62

siswa, 56, 57, 58, 59, 60, 61, 62

sosial, 22 